\title{
Challenges facing the Egyptian education system: Access, quality, and inequality
}

Caroline Krafft

Follow this and additional works at: https://knowledgecommons.popcouncil.org/departments_sbsr-pgy

Part of the Demography, Population, and Ecology Commons, Disability and Equity in Education Commons, Family, Life Course, and Society Commons, and the International Public Health Commons How does access to this work benefit you? Let us know!

\section{Recommended Citation}

Krafft, Caroline. 2012. "Challenges facing the Egyptian education system: Access, quality, and inequality," Survey of Young People in Egypt Policy Brief no. 2. Cairo: Population Council. 


\section{Survey of Young People in Egypt Policy Brief Series}

\section{CHALLENGES FACING THE EGYPTIAN EDUCATION SYSTEM Access, Quality, and Inequality}

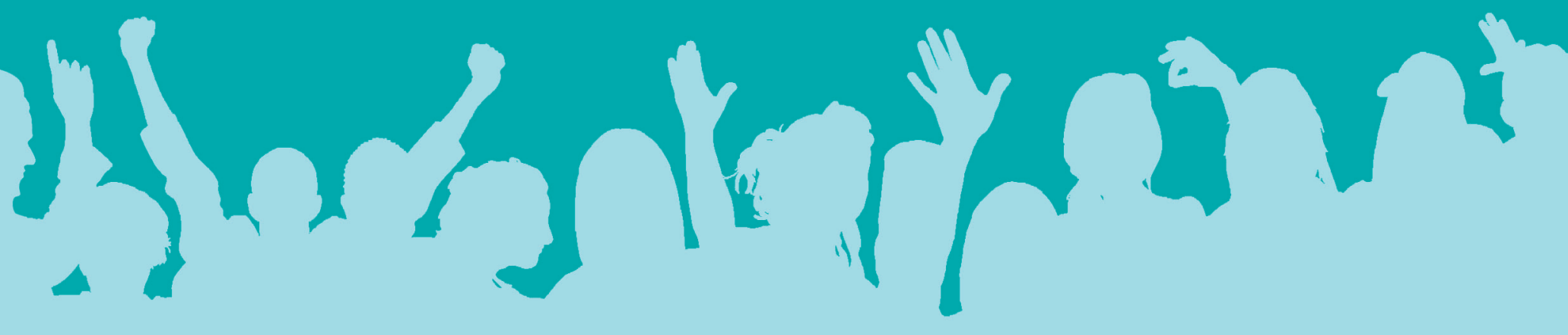

By Caroline Krafft

FORDFOUNDATION Working with Visionaries on the Frontlines of Social Change Worldwide
(2) Population Council Research that makes a difference 
$\mathrm{T}$ he purpose of education is to provide the knowledge and skills young people need to access economic, political, and social opportunities. Egypt has made substantial progress in ensuring that nearly all youth enter school. However, a persistently marginalized population, primarily of female youth in rural Upper Egypt, remains highly disadvantaged in accessing education. Egypt must implement alternative routes to education for those past school age, as well as policies such as conditional cash transfers to bring marginalized youth into the school system. Attending school is the means to obtaining an education, but not the end of education in and of itself. Egypt is failing to provide its youth with a high-quality education. Changes in pedagogy and curricula are vital to ensuring better educational and labor market outcomes. Moreover, the structure of the education system and the distribution of educational resources reinforce existing inequalities rather than providing opportunities for all youth.

\section{Key Messages}

- Access to school has improved, but some youth, especially females in rural Upper Egypt, remain outside the school system and are increasingly marginalized.

- The Egyptian school system is delivering lowquality education that is irrelevant to the labor market.

- Problems with repetition, absenteeism, and drop out reduce the efficiency of the education system.

- Unequal distribution of resources in the education system reinforces and increases existing inequalities in Egyptian society.

\section{Data and methods}

The recommendations of this brief are based on an analysis of the 2009 Survey of Young People in Egypt (SYPE). ${ }^{1}$ SYPE is a representative survey of 15,000 youth aged 10-29 in Egypt. The survey includes a detailed section on education with a variety of questions about educational attainment, experiences, and perceptions. This brief analyzes and summarizes young people's responses to these questions to identify the greatest challenges facing the Egyptian educational system, focusing specifically on primary through secondary schooling.

\section{Who is entering school?}

Egyptian youth are entering school at increasing rates. Figure 1 shows the percentage of youth born

${ }^{1}$ SYPE was conducted in cooperation with the Egyptian Cabinet's Information and Decision Support Center (IDSC) and funded by multiple donors. each year who ever entered school, by gender. For youth born in 1979, the oldest cohort observed in SYPE, around $95 \%$ of males entered school, but less than $85 \%$ of females did. Although male rates of school entry have improved slightly over time, the greatest improvement has been in female rates of school entry, which have risen above $95 \%$ for youth born after 1995 .

Figure 1: School entry by gender and year of birth

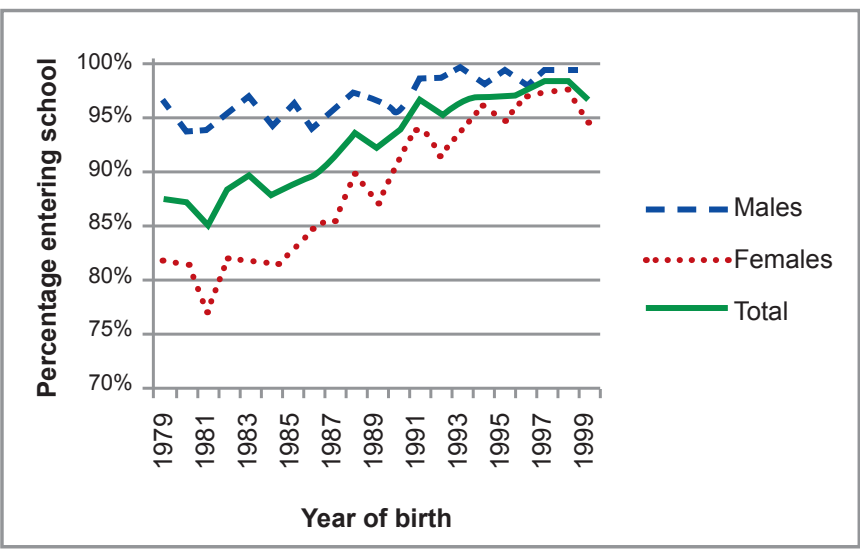

Although school entry has improved, there remains a substantial population of approximately two million youth aged 10-29, primarily females, who have never been to school and are now well past the age of entry. There also continues to be a persistent "mostmarginalized" group that fails to enter school. Looking across all 10-29-year-olds, rates of never-entry are quite low among the highest and fourth wealth quintiles, but increase exponentially with decreasing wealth, to the point that $27.2 \%$ of the poorest females and $7.4 \%$ of the poorest males never entered school. The highest rates of never-entry are observed in rural Upper Egypt, where $22.1 \%$ of female youth, more than 800,000 females, have never entered school. Even among the youngest generation of youth (aged 10-14) in Upper Egypt, 13.5\% of rural females and $11.1 \%$ of urban females never entered school. This represents a persistently marginalized population.

\section{Why do youth never enter school?}

In order to effect change, it is necessary to understand why these youth are not entering school and what can be done to change this. The most common reason youth never enter school is cultural. Over half of youth $(54.6 \%)$ listed parental disapproval, father disagreement, or customs and traditions as reasons for not entering school. The next most prevalent reason given was the cost of school $(32.0 \%){ }^{2}$ If cost presented an equal barrier to males and females, half of those giving cost as a reason for

\footnotetext{
2 The Egyptian constitution states that education is free of charge, however a substantial number of associated expenses, such as uniforms and materials, act as barriers to education.
} 
attending school should be female. However, among those giving cost as a reason for never attending, 76.9\% were female. This is clear resource discrimination against females. Cultural reasons were even more of a barrier to females: $88.5 \%$ of those giving such reasons were female. Although males were only $22.7 \%$ of those who never attended, they were $39.4 \%$ of those giving work as a reason for not attending. Cost reasons are also more common among poorer families, with $36.2 \%$ of youth from the poorest quintile giving cost as a reason for never entering school compared with $7.2 \%$ of youth from the wealthiest quintile. Finally, 15.8\% of youth who did not enter school did so because they "did not want to learn," $7.3 \%$ because of health reasons and $4.7 \%$ because there was no school in the area or the school was too far.

\section{How efficiently do schools educate youth?}

One important dimension of any schooling system is how efficiently it uses its resources; if children are absent from classes, repeat grades, or drop out of school before completing their education, the schooling system is not efficiently providing youth with an education. Absenteeism decreases effective learning time. Students in primary school are on average absent 5.4 days of the term, while preparatory students report 6.6 days. Secondary students report being absent nearly twice as often, at 11.2 days in vocational secondary school and 10.7 days in general secondary. Nearly a quarter $(23.9 \%)$ of vocational secondary students reported that one of their reasons for absence was that they do not benefit from school. More than a third $(39.0 \%)$ of general secondary students report being absent in order to study outside of school (see below for a further discussion of private tutoring). These are strong indications that during the time students spend in school, they are not efficiently instructed in relevant material.

More than a third of general secondary students report being absent from school in order to study outside of school.

One common inefficiency in the Egyptian educational system is grade repetition. When it takes a youth two years to master one year of material, this is an indication of both poor school quality and a waste of educational resources. In primary school, $5.8 \%$ of youth repeat at least one year, while during preparatory $11.2 \%$ of youth repeat. Repetition also persists in vocational secondary $(6.6 \%)$ and general secondary $(5.2 \%)$. This repetition is not evenly distributed by young people's backgrounds (Figure 2). Especially in primary and preparatory, youth from poorer wealth quintiles are much more likely to repeat.
Figure 2: Repetition by wealth quintile

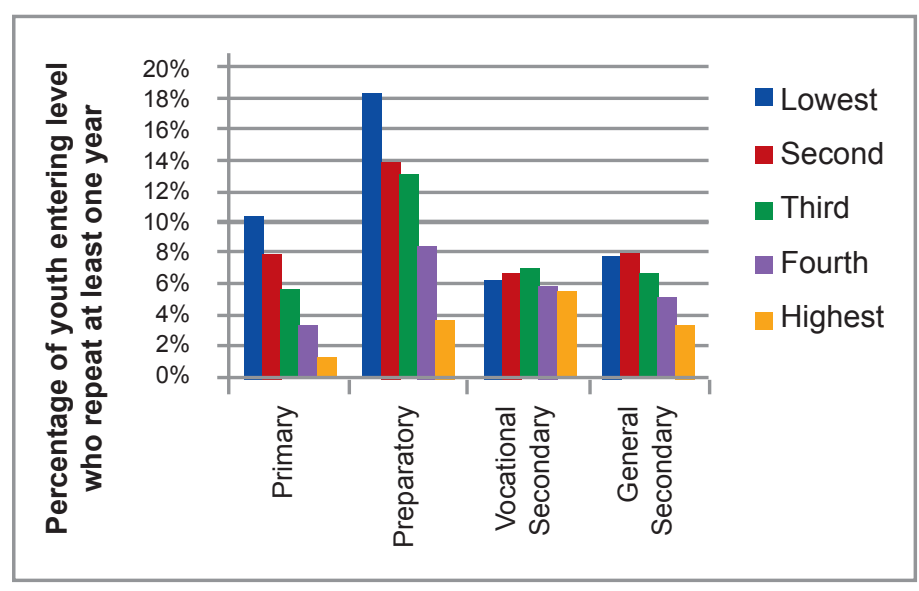

Once children enter school, an important issue is how long they stay there. Dropping out before the end of compulsory schooling (at the end of preparatory) or before acquiring job skills (at the end of vocational secondary or higher education) diminishes the benefit children receive from attending school. Figure 3 presents the "survival" of youth within the schooling system, i.e. the proportion of children attending each year, by wealth. It starts with the differences in entry, and shows the drop in attendance at the start of following years. ${ }^{3}$

Youth often drop out before completing their education, and strong differences in drop out occur by wealth. Generally, each wealth quintile experiences a higher rate of drop out than the next wealthier quintile, further spreading out survival within the schooling system. Thus, while the gap in the school entry rate between the richest and poorest quintiles is a $16.6 \%$ difference, $36.7 \%$ more of the highest quintile of youth complete preparatory, $41.7 \%$ more continue to secondary, and $67.1 \%$ more enter higher education.

Figure 3: Survival in school by wealth

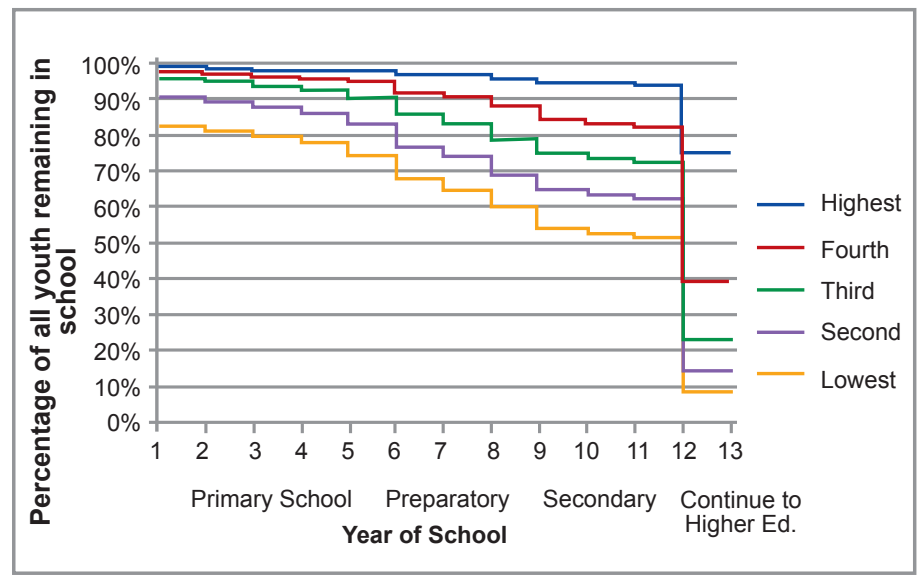

${ }^{3}$ Figure 3 accounts for the fact that many youth are still in school when calculating survival and drop out. 


\section{Are students gaining skills that will prepare them for adult life?}

One of the most important roles of education is to prepare youth for adult life. Literacy, numeracy, and job skills are key components of any education.

While $70.4 \%$ of current and past students report being satisfied with their schooling experience, only $57.8 \%$ of currently employed former students report being satisfied. Focusing only on 25-29 year olds, $70.1 \%$ of those out of the labor force report being satisfied with their education, whereas only $59.3 \%$ of those who are employed and $57.6 \%$ of those who are unemployed report being satisfied with their education. This indicates that those who are in a position to understand the relevance of their education to the labor market find it was subpar. Additionally, while a moderate $82.8 \%$ of current vocational secondary students in the industrial track reported that they had received any hands-on experience in school, only $63.9 \%$ of current students who received experience believed it was relevant to the needs of the labor market. Moreover, only 48.4\% of former vocational students who had received hands-on experience and were now employed reported that their training reflected the needs of the labor market. Thus, more than half of vocational students are receiving a "vocational" education that does not, in fact, prepare them for any vocation.

\section{Educational satisfaction}

Of the nearly $30 \%$ of students dissatisfied with their educational experience, pedagogical problems are the primary reason for the dissatisfaction. More than a third (39.1\%) of dissatisfied students report rote learning as a problem, and nearly half report poor treatment by teachers $(48.2 \%)$. More than half (60.9\%) report the difficulty of subjects as a reason for dissatisfaction, and a quarter (24\%) exams. Despite considerable infrastructural problems in Egyptian schools, ${ }^{4}$ and reasonably long commutes, few (less than 3\%) report the school building or commutes as the source of their dissatisfaction. Additional questions revealed that only $13.7 \%$ of all students report that they never have problems understanding teachers' explanations and only $14.1 \%$ of students say teachers always encourage student opinions. Overall, the picture that emerges is one of a poor curriculum, where subjects are rote and pedagogy is poor.

\section{Tutoring: Symptom of a flawed system}

Tutoring is a prominent feature of the education system. In Egypt, 58.4\% of current students receive

${ }^{4}$ Current students reported an average of 1.68 infrastructural problems out of a list of six items (multiple shifts, overcrowding, inadequate lighting, inadequate ventilation, broken seating, broken windows, or illegible blackboards). tutoring outside of school hours. Tutoring is used to help students succeed in Egypt's rigid exam-based progression system. Tutoring is especially prevalent for exams at the end of preparatory, which determine secondary placement, and at the end of general secondary, when scores determine university and faculty access. Figure 4 presents tutoring prevalence by wealth quintile and current school level. Tutoring is observed much more frequently among the wealthier quintiles, with $34.5 \%$ of the poorest primary students receiving tutoring, as compared with $75.9 \%$ of the wealthiest students. At the general secondary level, tutoring is as high as $93.3 \%$ among the wealthiest quintile. That students so often turn to tutoring to succeed is a strong signal that the school system inadequately educates its pupils.

Figure 4: Tutoring prevalence by wealth quintile and current school level

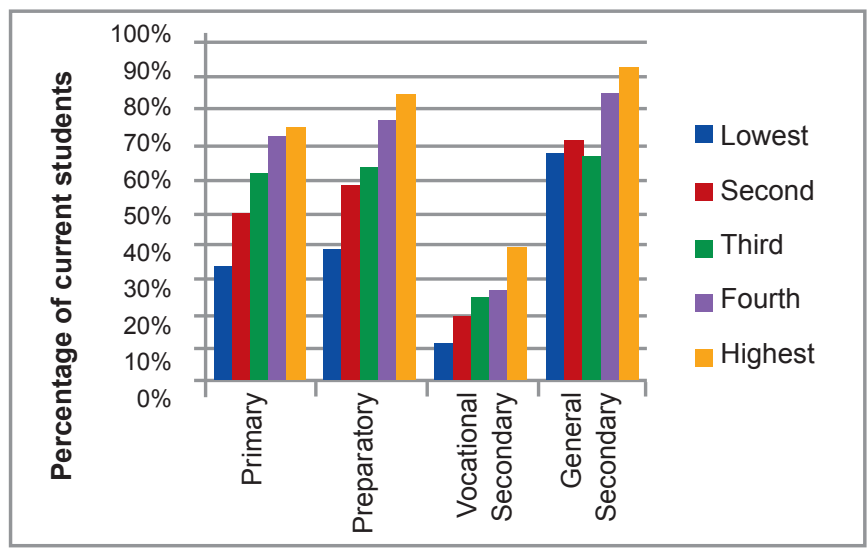

As Figure 5 illustrates, tutoring has a substantial cost burden. Families who are using tutoring and who are from the wealthiest quintile, at the general secondary level are spending an average of 330 LE per month (around \$US 55 at today's rates). This amount is more than half the income of a family of four at the national poverty line (656 LE) (El-Sherif 2010). Even the poorest families paying for tutoring at the primary level average a payment of $38 \mathrm{LE}$ a month, more than $5 \%$ of an impoverished family's income.

Figure 5: Tutoring cost by wealth quintile and current school level

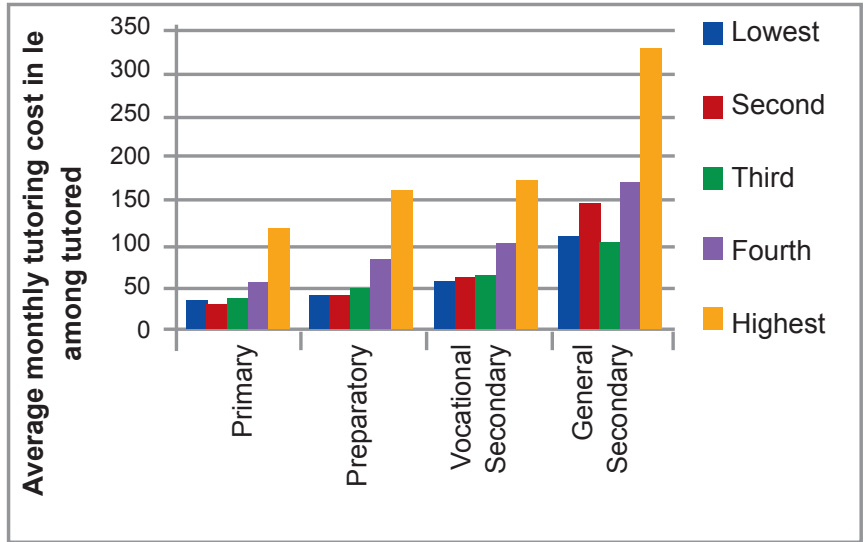




\section{Access, Efficiency, Quality Reforms Needed}

\section{Improving access}

A persistent minority of extremely marginalized and disadvantaged youth are never entering school. Among younger youth, work and cost reasons have become increasingly prevalent, whereas cultural reasons and not wanting to go have decreased. One potential policy that could help overcome financial reasons for never attending school is conditional cash transfers (CCTs). Cash transfers, conditional on youth (especially female youth) entering and continuing in school, incentivize schooling and also provide the money to pay school fees or to offset the lost income or chores of youth. ${ }^{5}$ Internationally, CCTs have proven an effective tool to get and keep marginalized youth in school (UNESCO 2010).

A variety of other interventions can target the other reasons for never entering school. The substantial portion $(15.8 \%)$ of never entering youth who did not want to learn might be reached by both improving the relevance of what is taught in schools and educating both young people and their parents on the importance of education. Transportation to school and targeted school-building programs would address the problem of access for the $4.7 \%$ of never entering youth who reported they had no school or the school was too far. Many (20\%) of the youngest youth (10-14) never entered school because of health reasons, indicating that there has been little progress in addressing this reason for never entering. Providing physical access to youth with health problems, as well as educational accommodations and support in schools would address that type of inaccessibility (UNESCO 2010).

Policies that provide youth (and adults) who are past school age with learning opportunities, such as literacy classes or second-chance schooling, also provide an important avenue to reach the substantial proportion of older youth who have never attended school. A piloted, culturally sensitive, second-chance schooling program for girls in rural Upper Egypt, Ishraq, has shown great success in reaching and educating this marginalized group (Brady et al. 2007).

\section{Providing relevant learning and effective teaching}

It is imperative that the Egyptian education system discard its current curricula and high-stakes exams focused on the rote memorization of irrelevant material.

\footnotetext{
${ }^{5}$ A pilot conditional cash transfer program is underway in two villages in Upper Egypt. See http://www.aucegypt.edu/ research/src/Pages/CCT.aspx
}

While entering and attending schools is an imperative first step to receiving an education, what youth take away from schools-what they learn and how well they learn it-is the essence of education. Egypt is failing to provide its youth with a relevant and quality education. This problem is visible in the educational process youth experience, especially high repetition, frequent drop out, and widespread tutoring, as well as youth perceptions of low school quality and the irrelevance of education to labor market needs. As a first step in addressing these issues, it is absolutely imperative for the Egyptian education system to discard its current curricula and high-stakes exams focused on the rote memorization of irrelevant material. As Figure 6 illustrates, these problems are the overriding reason that Egyptian youth fall short on fundamental skills and are unprepared for the labor market.

Tutoring is a powerful problem inextricably connected to Egypt's high-stakes examinations that focus on rote memorization. It is clear from SYPE that tutoring is a pervasive, expensive, and inequalityreinforcing problem in Egypt. It is estimated that household expenditures on tutoring in primary through secondary were approximately $1.6 \%$ of GDP (Bray 2003). As of 2007, Egypt spent 3.7\% of its GNP on education (UNESCO 2010). The fact that private expenditure on primary through secondary tutoring is nearly half the size of all public expenditure on education demonstrates that Egyptian families are willing to pay more for education. Additional taxation directed toward raising the quality of public education and altering the curriculum would be a far more equitable and efficient approach than tutoring. In the case of Egypt, it is generally teachers who are tutors, because they earn supplemental income from tutoring activities (Assaad and Elbadawy 2006). Raising the salaries and quality of teachers would also reduce their need to earn supplemental income as tutors.

Figure 6: Quality challenges and inequality in the education system

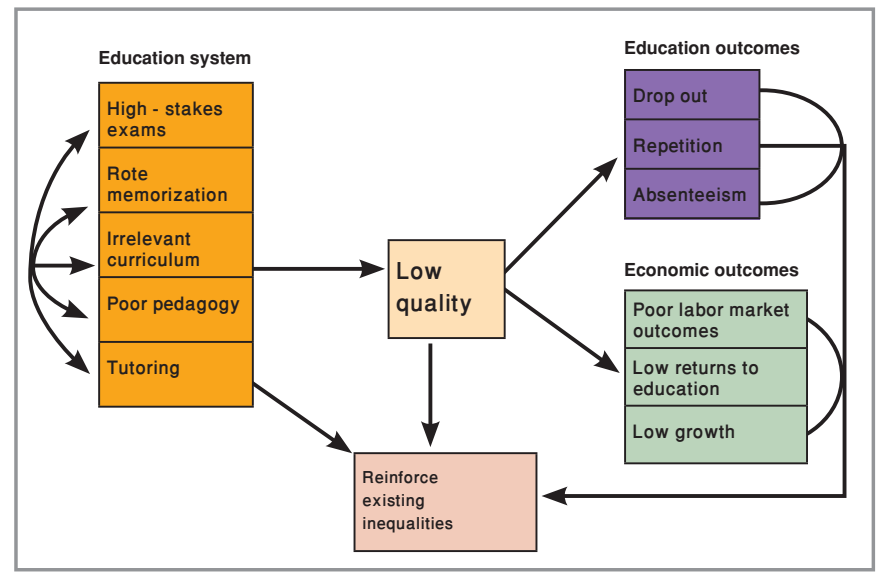


Pedagogical quality, the way in which teachers teach, is also critical to school quality. In Egypt, the primary activities in the classroom are copying from the blackboard, writing, and listening to teachers (World Bank 2008). While Egypt has set as its goal a series of pedagogical reforms to move toward student-centered learning, youth responses in SYPE indicate that these reforms have not yet been realized in the classroom. The other countries in the region that are performing better on school outcomes have more fully adopted student-centered learning practices (World Bank 2008), suggesting a path for Egypt to follow. Improving quality will also be less costly than it appears since improved quality reduces absenteeism, repetition, and drop out.

Strong fundamental skills, as well as higher-order cognitive skills, such as critical thinking, judgment, and flexibility, are important for success in the evolving and modernizing labor market (World Bank 2002). Egypt's lack of appropriate pedagogy and curricula are why half of employed students find their education not relevant to the labor market. This mismatch between what students learn and what the labor market needs is a major contributor to high unemployment and sluggish national growth (World Bank 2008).

Improving quality will be less costly than it appears since improved quality reduces absenteeism, repetition, and drop out.

\section{Change the Distribution of Educational Resources So Schools Provide Opportunity Rather Than Reinforce Inequality}

Education is vital to providing youth with opportunities that supersede any disadvantage that they may have been born into. School resources can counter socioeconomic disadvantages (UNESCO 2010). However, Egypt currently deploys school resources unevenly, so that socioeconomically disadvantaged students also face disadvantages in school. For instance, poorer students reported more school infrastructure problems. Public expenditures must be altered to ensure equity in school environments, regardless of where or to whom one is born. Redistribution that favors more disadvantaged communities is also warranted to provide more equal opportunities to disadvantaged youth.

\section{References}

Assaad, R. and A. Elbadawy. 2006. "Private and Group Tutoring in Egypt: Where is the Gender Inequality?" Conference paper. Estuarine Research Federation Conferences.

Brady, M., R. Assaad, B. Ibrahim, A. Salem, R. Salem, N. Zibani. 2007. Providing New Opportunities to Adolescent Girls in Socially Conservative Settings: The Ishraq Program in Upper Egypt. New York: Population Council.

Bray, M. 2003. Adverse Effect of Private Supplementary Tutoring: Dimensions, Implications and Government Responses. Paris: UNESCO International Institute for Educational Planning. (Ethics and Corruption in Education series.)

El-Sherif, H. 2010. "Average Income of Government Employee LE 98, says study," Daily News Egypt. 7 April 2010. http://www.thedailynewsegypt. com/archive/average-income-of-govt-employee-le-98-says-study.html. Accessed 19 September 2011.

Krafft, Caroline and Safaa El Kogali. 2011. "Education," in Survey of Young People in Egypt Final Report. Cairo: Population Council.

UNESCO. 2010. EFA Global Monitoring Report: Reaching the Marginalized. Paris: UNESCO.

World Bank. 2002. Arab Republic of Egypt: Education Sector Review: Progress and Priorities for the Future. Report No. 24905-EGT. The World Bank.

World Bank. 2008. The Road Not Traveled: Education Reform in the Middle East and Africa. MENA Development Report. Washington, DC: The World Bank.

The Population Council confronts critical health and development issues-from stopping the spread of HIV to improving reproductive health and ensuring that young people lead full and productive lives. Through biomedical, social science, and public health research in 50 countries, we work with our partners to deliver solutions that lead to more effective policies, programs, and technologies that improve lives around the world. Established in 1952 and headquartered in New York, the Council is a nongovernmental, nonprofit organization governed by an international board of trustees. 